Journal of Animal and Veterinary Advances 10 (7): 909-913, 2011

ISSN: $1680-5593$

(C) Medwell Journals, 2011

\title{
The Pathogenesis of Salmonella enterica Serovar Enteritidis in Subcutaneously Infected Pigeon: A Quantitative Time-Course Study Using Real-Time PCR
}

\author{
${ }^{1}$ Guang-Zhi He, ${ }^{1}$ Wei-Yi Tian, ${ }^{1}$ Ning Qian and ${ }^{2}$ Shu-Xuan Deng \\ ${ }^{1}$ Guiyang College of Traditional Chinese Medicine, 550002 Guiyang, Guizhou Province, China \\ ${ }^{2}$ Agricultural Office of Dalingshan Town, 523830 Dongguan, Guandong Province, China
}

\begin{abstract}
This research was undertaken to determine the pathogenesis of a high-virulence strain of Salmonella enterica serovar Enteritidis in pigeon by a fluorescent quencher PCR assay and to correlate these findings with the results obtained from the immunohistochemical localization and histopathological examinations of selected Salmonella enterica serovar Enteritidis-infected tissues. To make the results meaningful, a side-by-side bacteriology method (indirect immuno-fluorescent antibody staining) was performed too. Pigeons were subcutaneously infected with a high-virulence strain of Salmonella enterica serovar Enteritidis. The kinetics of the Salmonella enterica serovar Enteritidis genomic DNA loads, the immunohistochemical localization of the bacterial antigens and the histopathological examination in various tissues were investigated. The results showed that at $12 \mathrm{~h}$ postinoculation, high Salmonella enterica serovar Enteritidis DNA loads were observed in various organs of the infected pigeons. Thereafter, the bacterial DNA loads increased by various amounts until $36 \mathrm{~h}$ postinoculation and the pigeons exhibited typical clinical signs of the infection. Extremely high bacterial DNA loads were observed in the pigeons at 36 and $48 \mathrm{~h}$ postinoculation compared with those observed at 8-24 h postinoculation. The results of indirect immuno-fluorescent antibody staining were similar to the fluorescent quencher PCR assay. The time course of the appearance of bacterial antigens and tissue lesions in various tissues was coincident with the levels of the bacterial DNA loads at the infection sites. This suggests that Salmonella enterica serovar Enteritidis loads in internal organs are closely correlated with the progression of the infection.
\end{abstract}

Key words: $S$. enteritidis, quantitative study, pigeon, infection, organs, FQ-PCR

\section{INTRODUCTION}

A significant proportion of all cases of human salmonellosis are known to be caused by the consumption of raw or partially cooked eggs (Hope et al., 2002; Massi et al., 2006; Xu et al., 2007). Salmonella enterica serovar Enteritidis (S. enteritidis) is responsible for most causes of gastrointestinal infection in the world (Gillespie et al., 2005).

Due to the increased prevalence of $S$. enteritidis and its complex pathogenesis, it is important to understand the correlation between the levels of this bacterium in internal organs and the progression of the infection (Agron et al., 2001; Deng et al., 2008; Lai et al., 1992; Okamura et al., 2005) this has not been previously described in pigeon.

Generally, little is known about the pathogenesis of $S$. enteritidis in pigeon after $S$. enteritidis-infected. Up to day, the mechanisms by which $S$. enteritidis and other serotypes persist within the host and the reasons for the absence of immune clearance are not known. Understanding this correlation will help gain further, insight into the pathogenesis of $S$. enteritidis infections.

\section{MATERIALS AND METHODS}

Bacterial strains: A high-virulence strain of $S$. enteritidis (isolated from the intestinal content of S. enteritidis-infected mouse in 2005; phage type 4; no: 50338) was purchased from the National Center for Medical Culture Collection.

Experimental animals and samples: About 4 weeks old pigeons free from $S$. enteritidis infection were used in the study. Prior to challenge with $S$. enteritidis, all pigeons were found to be negative for $S$. enteritidis specific antibodies and $S$. enteritidis specific antigens by an enzyme-linked immunosorbent assay and PCR, respectively (Deng et al., 2008; Gast and Beard, 1990).

Corresponding Author: Guang-Zhi He, Guiyang College of Traditional Chinese Medicine, 550002 Guiyang, Guizhou Province, China 
The pigeons were maintained in isolation units in a biosecure animal building. In brief, $S$. enteritidis cells were grown overnight in a Luria-Bertani broth. The cells were cultured overnight and then the presumptive live number of $S$. enteritidis cells was determined by the spread plate method. Thereafter, a group of 48 pigeons were subcutaneously injected with a high-virulence S. enteritidis strain (phage type 4; no.: 50338; inoculation site, back). Animal experiments were reviewed by an Institutional Animal Care and Use Committee (IACUC) for human use of animal for experimental purposes. Each pigeon was inoculated with $4.0 \times 10^{4}$ cells in $0.2 \mathrm{~mL}$ of water. Another group of 36 pigeon was treated with an equal volume of water and used as a control group. The liver, spleen, lung, kidney, jejunum, ileum, rectum and cecum were analyzed by a fluorescent quencher PCR assay at postinoculation times of $30 \mathrm{~min} ; 1,2,4,8,12,24,36 \mathrm{~h}$ and 2, 3, 6 and 9 day. At each time point, 3 pigeons were randomly selected from the infection and control groups and their tissue samples were collected and processed for further analyses.

DNA extraction from the tissue samples was performed as described previously (Deng et al., 2008; He et al., 2010). Briefly, $0.5 \mathrm{~g}$ of the tissue sample was ground up using a tissue grinder in the $1.5 \mathrm{~mL}$ Eppendorf tube.

The pellet was resuspended in $500 \mu \mathrm{L}$ TE buffer ( $\mathrm{pH} 8.0$ ) with $10 \mu \mathrm{L}$ Proteinase $\mathrm{K}\left(30 \mathrm{~g} \mathrm{~L}^{-1}\right)$ and incubated at $37^{\circ} \mathrm{C}$ for $2 \mathrm{~h}$. Finally with a conventional phenol/chloroform/isoamyl alcohol method to extract the genomic DNA of $S$. enteritidis from tissue, DNA genomic pillet was resuspended in $50 \mu \mathrm{L}$ TE buffer. Researchers used $5 \mu \mathrm{L}$ aliquot of DNA template for fluorescent quencher PCR detection.

Quantitative real-time PCR assay for detection of S. enteritidis DNA: In the previous study, researchers have established a serovar specific real-time PCR assay (Genbank accession no. AF 370707.1) the limit of detection was 70 copies $\mathrm{g}^{-1}$ (Agron et al., 2001; Deng et al., 2008; He et al., 2010). Brifely, a real-time PCR assay was carried out using a real-time PCR core kit (R-PCR version 2.1, TaKaRa, Japan) with an Icycler $\mathrm{iQ}^{\mathrm{TM}}$ real-time PCR detection system (version 3.1, Bio-Rad, USA) and was performed as described previously. PCR amplification was performed in a $25 \mu \mathrm{L}$ reaction mixture containing $0.6 \mu \mathrm{L}$ of each primer (10 $\left.\mu \mathrm{mol} \mathrm{L}^{-1}\right), \quad 0.75 \mu \mathrm{L}$ deoxyribonucleotide Triphosphates (dNTPs) $\left(10 \mathrm{mmol} \mathrm{L}^{-1}\right), 1.25 \mathrm{U}$ Ex Taq DNA Polymerase (TaKaRa Ex Taq Hot Start version, Takara, Japan), $5 \mu \mathrm{L}$ of $5 \times \mathrm{PCR}$ buffer (free $\mathrm{Mg}^{2+}$ ), $0.8 \mu \mathrm{L}$ TaqMan probe $\left(5 \mu \mathrm{mol} \mathrm{L}^{-1}\right), 0.5 \mu \mathrm{L} \mathrm{Mg}^{2+}\left(250 \mathrm{mmol} \mathrm{L}^{-1}\right)$ and $5 \mu \mathrm{L}$ templates. The reaction mixture was subsequently made up to a volume of $25 \mu \mathrm{L}$ with deionized water. Each PCR run consisted of a $5 \mathrm{~min}$ hot start at $95^{\circ} \mathrm{C}$ which activated the conjugated polymerase, followed by 40 cycles consisting of $30 \mathrm{sec}$ of denaturation at $94^{\circ} \mathrm{C}, 30 \mathrm{sec}$ of annealing at $55^{\circ} \mathrm{C}$ and a fluorescent read step. In this study, it was used the real-time PCR assay specific to serovars to study the $S$. enteritidis loads in various pigeon tissues following subcutaneous infection.

Immunohistochemical localization of $S$. enteritidis antigen: Small pieces of tissues were collected and fixed in $10 \%$ neutral buffered formalin, processed for paraffin embedding and sectioned at a thickness of $5 \mu \mathrm{m}$. The sections were stained for $S$. enteritidis antigen within different samples by using the avidin-biotin-peroxidase complex method (Islam et al., 1993).

Histopathological examination: For histopathological examination, the paraffin-embedded sections were cut at $5 \mu \mathrm{m}$ thickness and stained with haematoxylin and eosin (Mutinelli et al., 2003).

Indirect immuno-fluorescent antibody staining detection: A side by side quantitative bacteriology was performed to determine the bacterial burdens in these corresponding tissues and compare these data with the PCR data. In a previous study, a specific method of indirect Immuno-Fluorescent Antidody staining (IFA) for $S$. enteritidis was established (Yan et al., 2008). This research based on the IFA assay to study the distribution pattern and quantity for $S$. enteritidis in the internal organs of pigeon after subcutaneously infected.

Statistical analysis: The PCR assay and data acquisition and analysis were performed using the iCycler IQ Optical system software (version 3.1; Bio-Rad, USA). The number of target copies in the reaction was deduced from the threshold cycle values. The threshold cycle value corresponds to the fractional cycle number at which the fluorescence emission exceeds the standard deviation of the mean baseline emission by 15 fold. Plasmid DNA containing the target amplicon was diluted to contain $7.0 \times 10^{2}-7.0 \times 10^{8}$ copies of the target DNA per test tube and used as the plasmid standard series. All samples were analyzed 3 times by the real time PCR assay and concentrations of the target DNA detected were expressed as the mean $\log _{10}$ of the bacterial genome copy number per gram of tissue tested.

The real-time PCR data were analyzed using version 11 of the SPSS software. The comparison of 
Table 1: Kinetics of S. enteritidis DNA loads in pigeon subcutaneously injected with a high-virulence strain determined by quantitative real-time PCR Time

\begin{tabular}{|c|c|c|c|c|c|c|c|c|c|}
\hline$\underline{\text { Tissues }}$ & $30 \mathrm{~min}$ & $1 \mathrm{~h}$ & $2 \mathrm{~h}$ & $4 \mathrm{~h}$ & $8 \mathrm{~h}$ & $12 \mathrm{~h}$ & $24 \mathrm{~h}$ & $36 \mathrm{~h}$ & 2 days \\
\hline Liver & $0.00 \pm 0.00$ & $0.00 \pm 0.00$ & $0.00 \pm 0.00$ & $2.58 \pm 0.35^{\mathrm{A}}$ & $2.49 \pm 0.51^{\mathrm{D}}$ & $4.24 \pm 0.67^{\mathrm{F}}$ & $5.77 \pm 0.82^{\mathrm{I}}$ & $6.65 \pm 0.23^{\mathrm{M}}$ & $6.33 \pm 0.81^{\mathrm{R}}$ \\
\hline Spleen & $0.00 \pm 0.00$ & $0.00 \pm 0.00$ & $0.00 \pm 0.00$ & $2.33 \pm 0.21^{\mathrm{A}}$ & $3.49 \pm 0.69^{\mathrm{C}}$ & $4.68 \pm 0.51^{\mathrm{F}}$ & $7.01 \pm 0.52^{\mathrm{J}}$ & $8.91 \pm 0.57^{\mathrm{N}}$ & $9.95 \pm 0.37^{\mathrm{s}}$ \\
\hline Lung & $0.00 \pm 0.00$ & $0.00 \pm 0.00$ & $0.00 \pm 0.00$ & $0.00 \pm 0.00^{\mathrm{B}}$ & $0.00 \pm 0.00^{\mathrm{E}}$ & $2.38 \pm 0.14^{G}$ & $4.53 \pm 0.66^{\mathrm{K}}$ & $5.47 \pm 0.31^{\circ}$ & $8.20 \pm 0.32^{\mathrm{T}}$ \\
\hline Kidney & $0.00 \pm 0.00$ & $0.00 \pm 0.00$ & $0.00 \pm 0.00$ & $0.00 \pm 0.00^{\mathrm{B}}$ & $2.25 \pm 0.60^{D}$ & $3.47 \pm 0.43^{\mathrm{H}}$ & $4.11 \pm 0.27^{\mathrm{k}}$ & $5.12 \pm 0.31^{\circ}$ & $7.80 \pm 0.22^{\mathrm{t}}$ \\
\hline Jejunum & $0.00 \pm 0.00$ & $0.00 \pm 0.00$ & $0.00 \pm 0.00$ & $0.00 \pm 0.00^{\mathrm{B}}$ & $2.87 \pm 0.75^{\mathrm{d}}$ & $3.79 \pm 0.59^{\mathrm{H}}$ & $6.11 \pm 0.15^{\mathrm{i}}$ & $7.62 \pm 0.52^{\mathrm{P}}$ & $8.42 \pm 0.62^{\mathrm{T}}$ \\
\hline Ileum & $0.00 \pm 0.00$ & $0.00 \pm 0.00$ & $0.00 \pm 0.00$ & $0.00 \pm 0.00^{\mathrm{B}}$ & $3.24 \pm 0.21^{\mathrm{C}}$ & $4.41 \pm 0.25^{\mathrm{F}}$ & $6.26 \pm 0.51^{\mathrm{i}}$ & $7.89 \pm 0.21^{\mathrm{P}}$ & $8.51 \pm 0.19^{\mathrm{T}}$ \\
\hline Rectum & $0.00 \pm 0.00$ & $0.00 \pm 0.00$ & $0.00 \pm 0.00$ & $0.00 \pm 0.00^{\mathrm{B}}$ & $0.00 \pm 0.00^{E}$ & $2.72 \pm 0.57^{\mathrm{G}}$ & $3.57 \pm 0.53^{\mathrm{L}}$ & $4.29 \pm 0.23^{Q}$ & $5.38 \pm 0.14^{\mathrm{U}}$ \\
\hline Cecum & $0.00 \pm 0.00$ & $0.00 \pm 0.00$ & $0.00 \pm 0.00$ & $0.00 \pm 0.00^{\mathrm{B}}$ & $0.00 \pm 0.00^{\mathrm{E}}$ & $4.48 \pm 0.20^{\mathrm{F}}$ & $5.49 \pm 0.90^{I}$ & $5.68 \pm 0.19^{\circ}$ & $7.19 \pm 0.68^{V}$ \\
\hline
\end{tabular}

a) All the infected pigeons died at 2 day postinoculation. Each time point represents the mean concentration of genomic DNA and is expressed as log 10 of the bacterial genome copy number per $\mathrm{g}$ of tissue tested $\pm \mathrm{SD}$ obtained from 3 pigeons. Each sample was analyzed 3 times by the fluorescent quencher PCR assay. In this study, researchers get the mean from 9 tests for each sample and the 9 results were not different for each sample ( $p>0.05$ ); $b$ ) no significant differences between the 8 groups $(\mathrm{p}>0.05$ ) at $30 \mathrm{~min}$ to $2 \mathrm{~h}$ postinoculation; values with different superscripts within a column followed by different letters were significantly different between eight groups $(\mathrm{p}<0.01)$; values with different superscripts within a column followed by lower case and capital of the same letter were different between 8 groups $(\mathrm{p}<0.05)$; values within a column followed by same letters were not different between eight groups $(\mathrm{p}>0.05) ; \mathrm{c})$ Min $=\min , \mathrm{h}=\mathrm{h}, \mathrm{d}=$ day

means was performed using Duncan's multiple range test. A p-value $<0.05$ was considered statistically significant.

\section{RESULTS AND DISCUSSION}

In this study, the acute stage of an $S$. enteritidis infection in pigeons caused by a high-virulence strain of the pathogen was investigated with regard to the kinetics of the bacterial DNA loads, the localization of the bacterial antigens and histopathological examinations in various tissues. At $12 \mathrm{~h}$ postinoculation, high $S$. enteritidis DNA loads were observed in various organs of the infected pigeons (Table 1). Thereafter, the bacterial DNA loads increased by various amounts until $36 \mathrm{~h}$ postinoculation and the pigeons exhibited typical clinical signs of the infection (Table 1). After $36 \mathrm{~h}$ postinoculation, some pigeons were still alive. At 2 day postinoculation, the remaining 12 infected pigeons died as a result of the infection. About 3 dead pigeons were randomly selected for tissue sample analysis. Severe hemorrhage, some necrotic foci in the parenchymatous organs and hemorrhagic enteritis were the predominant gross pathological findings in the dead pigeons. Extremely high bacterial DNA loads were observed in the pigeons at 36 and $48 \mathrm{~h}$ postinoculation compared with those observed at 8-24 $\mathrm{h}$ postinoculation (Table 1). The results of quantitative real-time PCR, immunohistochemical localization and histopathological examination revealed that the time course of the appearance of bacterial antigens and tissue lesions in various tissues was coincident with the levels of the bacterial DNA loads at the infection sites. These results demonstrate that the wide spread dissemination of $S$. enteritidis to infection in various organs increases with progression of the infection. An important finding of this study was that during the course of infection, the lymphoid and intestinal organs, especially the spleen, jejunum and ileum, contained relatively higher bacterial DNA loads than the other organs investigated (Table 1).

Immunohistochemical analysis revealed high levels of expression of the $S$. enteritidis antigen in the epithelial cells and lymphocytes of the jejunum, ileum. High levels of this antigen were also noted in some lymphocytes of the spleen. Histological examination revealed lymphoid organ lesions including lymphoid depletion and necrosis and epithelial hypertrophy of the bursa. In the intestine, the $S$. enteritidis antigen was localized to the surface epithelium and the epithelial crypt cells and also to the macrophages and fibroblasts of the lamina propria. Sheets of epithelial cells displaced from the villi surface were observed in the infected ileum. Furthermore, all the examined infected organs demonstrated vascular damage, severe hyperemia and hemorrhage. These results suggest the probability that the lymphoid and intestinal organs are the major target organs of $S$. enteritidis replication and that the epithelial cells and lymphocytes probably serve as the principal sites of bacterial replication. Furthermore, the high levels of bacteria DNA in these tissues might reflect the presence of abundant target epithelial and lymphoid cells in these tissues (Abshire and Neidhardt, 1993; Cirillo et al., 1998; Dunlap et al., 1991; Dibb-Fuller et al., 1999; Takata et al., 2003). Therefore, it can be inferred that these cells play a key role in the pathogenesis of acute $S$. enteritidis infections which manifests as severe lesions in the lymphoid organs and small intestine. The kinetics of the bacterial DNA loads in the other parenchymatous organs varied. At $8 \mathrm{~h}$ postinoculation before the appearance of clinical signs of the infection, it was observed that the liver tissues contained significantly high levels of $S$. enteritidis than the lungs and the kidneys (Table 1). However in dead 

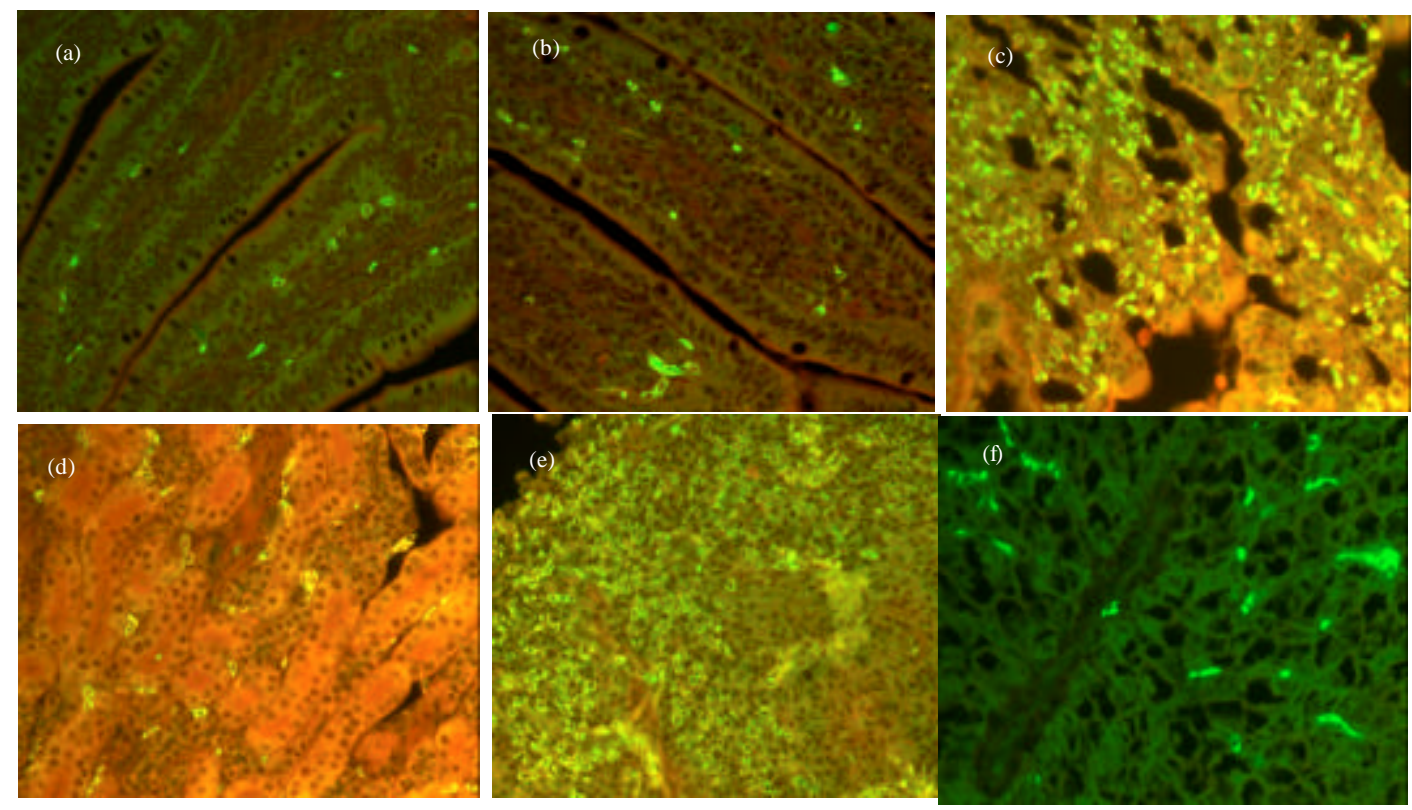

Fig. 1: Used indirect immunofluorescents antidody staining assay to detected infected-groud at $8 \mathrm{~h}$ and 2 days PI. Bar $=50 \mu \mathrm{m} ; \mathrm{a}$ ): jejunum from $8 \mathrm{~h}$ PI presented positive signal; b): rectum from $12 \mathrm{~h}$ PI presented positive signal; c): kidney from $24 \mathrm{~h} \mathrm{PI}$, present positive signal; d): liver from $12 \mathrm{~h}$ PI presented psotive signal; e): lung from 2 days PI presented strong psotive signal and $\mathrm{f}$ ): spleen from 2 days PI presented strong psotive signal

pigeons, the bacterial concentration in the lungs and kidneys was higher than that in the liver tissues. In the liver, bacterial antigen-containing hepatocytes were mainly observed within necrotic foci or around blood vessels. The $S$. enteritidis antigen was also found in the epithelial cells of the alveoli and the tubular epithelial cells of the kidney.

The following pathological features were observed in the organs examined: swollen tubular epithelial cells and nephrosis in the kidney, necrotic foci and varying degrees of hepatocyte fat degeneration of hepatocytes in the liver, slightly hyperemic and hemorrhagic cribriform changes in the brain. Severe hyperemia, hemorrhages and heterophil infiltration in the lungs were also observed.

The overall pattern of antigen distribution and microscopic lesions in the organs examined were similar to those reported in previous studies (Akaki et al., 1997; Deng et al., 2007, 2008; Holt and Jr Porter, 1992; Yan et al., 2008). The factors that determine the levels of $S$. enteritidis load in various tissues have not been fully understood however, the high $S$. enteritidis DNA loads in multiple internal organs results in severe tissue pathology which accelerates the progression of the infection. The control group did not generate any positive results, at any time point of the study at any location. This study provided valuable insights into the etiology and pathogenesis of $S$. enteritidis infections in pigeon. To validate the results, this research simultaneously performed a quantitative bacteriological test to determine the bacterial burden in the corresponding tissues and compare these data with the FQ-PCR data. The results of IFA were similar to the FQ-PCR assay (Fig. 1a-f). Therefore, this research is very accurate for studying the replication kinetics of $S$. enteritidis in the internal organs and will help to improve the understanding of $S$. enteritidis and its pathogenesis.

\section{CONCLUSION}

This study indicated that the S. enteritidis load in internal organs was observed to be closely correlated with the progression of the infection. The high bacterial loads and the high levels of replication in the lymphoid and small-intestinal tissues might reflect the presence of abundant target epithelial and lymphoid cells in these tissues.

\section{ACKNOWLEDGEMENT}

The research was supported by Science and Technology Agency of Guizhou province, no. 2010 (2262). 


\section{REFERENCES}

Abshire, K.Z. and F.C. Neidhardt, 1993. Analysis of proteins synthesized by Salmonella typhimurium during growth within a host macrophage. J. Bacteriol., 175: 3734-3743.

Agron, P.G., R.L. Walker, H. Kinde, S.J. Sawyer, D.C. Hayes, J. Wollard and G.L. Andersen, 2001. Identification by subtractive hybridization of sequences specific for Salmonella enterica serovar enteritidis. Appl. Environ. Microbiol., 67: 4984-4991.

Akaki, C., M. Shimazu, T. Baba, S. Tsuji, H. Kodama, M. Mukamoto and T. Kajikawa, 1997. Possible migration of harderian gland immunoglobulin a bearing lymphocytes into the caecal tonsil in chickens. J. Vet. Med. Ser. B, 44: 199-206.

Cirillo, D.M., R.H. Valdivia, D.M. Monack and S. Falkow, 1998. Macrophage-dependent induction of the Salmonella pathogenicity island 2 type III secretion system and its role in intracellular survival. Mol. Microbiol., 30: 175-188.

Deng, S.X., A.C. Cheng, M.S. Wang and P. Cao, 2007. Gastrotestinal tract distribution of Salmonella enteritidis in orally infected mice with a speciesspecific fluorescent quantitative polymerase chain reaction. World J. Gastroenterol., 13: 6568-6574.

Deng, S.X., A.C. Cheng, M.S. Wang and P. Cao, 2008. Serovar-specific real-time quantitative detection of Salmonella enteritidis in the gastrointestinal tract of ducks after oral challenge. Avian Dis., 52: 88-93.

Dibb-Fuller, M.P., E. Allen-Vercoe, C.J. Thorns and M.J. Woodward, 1999. Fimbriae- and flagellamediated association with and invasion of cultured epithelial cells by Salmonella enteritidis. Microbiology, 145: 1023-1031.

Dunlap, N.E., W.H. Jr Beniamin, R.D. Jr McCall, A.B. Tilden and D.E. Briles, 1991. A safe site for Salmonella typhimurium is within splenic cells during the early phase of infection in mice. Microb. Pathogenesis, 10: 297-310.

Gast, R.K. and C.W. Beard, 1990. Serological detection of experimental Salmonella enteritidis infections in laying hens. Avian Dis., 34: 721-728.

Gillespie, I.A., S.J. Brien, G.K. Adak, L.R. Ward and H.R. Smith, 2005. Foodborne general outbreaks of Salmonella enteritidis phage type 4 infection, Englang and Wales, 1992-2002: Where are the risks? Epidemiol. Infect., 133: 795-801.
He, G.Z., W.Y. Tian, N. Qian, A.C. Cheng and S.X. Deng, 2010. Quantitative studies of the distribution pattern for Salmonella enteritidis in the internal organs of chicken after oral challenge by a real-time PCR. Vet. Res. Commun., 34: 669-676.

Holt, P.S. and R.E. Jr Porter, 1992. Microbiological and histopathological effects of an induced-molt fasting procedure on a Salmonella enteritidis infection in chickens. Avian Dis., 36: 610-618.

Hope, B.K., A.R. Baker, E.D. Edel, A.T. Hogue and W.D. Schlosser et al., 2002. An overview of the Salmonella enteritidis risk assessment for shell eggs and egg products. Risk Anal., 22: 203-218.

Islam, M.R., J. Nessa and K.M. Halder, 1993. Detection of duck plague virus antigen in tissues by immunoperoxidase staining. Avian Path., 22: 389-393.

Lai, C.W., R.C. Chan, A.F. Cheng, J.Y. Sung and J.W. Leung, 1992. Common bile duct stones: A cause of chronic salmonellosis. Am. J. Gastroenterol., 87: 1198-1199.

Massi, M., P. Ioan, R. Budriesi, A. Chiarini and B. Vitali et al., 2006. Effects of probiotic bacteria on gastrointestinal motility in guinea-pig isolated tissue. World J. Gastroenterol., 12: 5987-5994.

Mutinelli, F., I. Capua, C. Terregino and G. Cattoli, 2003. Clinical, gross and microscopic findings in different avian species naturally infected during the H7N1 low- and high-pathogenicity avian influenza epidemics in Italy during 1999 and 2000. Avian Dis., 47: 844-848.

Okamura, M., H.S. Lillehoj, R.B. Raybourne, U.S. Babu and R.A. Heckert et al., 2005. Differential responses of macrophages to Salmonella enterica serovars Enteritidis and Typhimurium. Vet. Immunol. Immunpathol., 107: 327-335.

Takata, T., J. Liang, H, Nakano and Y. Yoshimura, 2003. Invasion of Salmonella enteritidis in the tissues of reproductive organs in laying Japanese quail: An immunocytochemical study. Poult. Sci., 82: 1170-1173.

Xu, C., Z.S. Li, Y.Q. Du, Y.F. Gong, H. Yang, B. Sun and J. Jin, 2007. Construction of recombinant attenuated Salmonella typhimurium DNA vaccine expressing $\mathrm{H}$ pylori ure $\mathrm{B}$ and $\mathrm{IL}-2$. World J. Gastroenterol., 13: 939-944.

Yan, B., A.C. Cheng, M.S. Wang, S.X. Deng and Z.H. Zhang et al., 2008. Application of an indirect immunofluorescent staining method for detection Salmonella enteritidis in paraffin slices and antigen location in infected duck tissues. World J. Gastroenterol., 14: 776-781. 